\title{
Performance of Foreign-Invested Enterprises in Shaanxi - An Empirical Analysis
}

\author{
Tao Wang', Duo Wang ${ }^{2}$ \\ ${ }^{1}$ School of Economics and Management, XIDIAN University, 266 Xinglong Section of Xifeng Road, Xi'an, Shaanxi 710126, China \\ ${ }^{2}$ School of Economics and Management, XIDIAN University, 266 Xinglong Section of Xifeng Road, Xi'an, Shaanxi 710126, China
}

\begin{abstract}
Since the reform and opening up, the role of foreign investment should not be overlooked. However, FDI showing a large area of loss in China in recent years, and the loss rate is more than 50\%. Facing with such serious losses of FDI, we should carefully explore the main factors that affect foreign-invested enterprises' management, and research the possible reasons that cause the operating loss of the FDI. This paper mainly uses the method of empirical research, the data are form the financial information of 1165 foreign-invested enterprises which participated the joint inspection of Shaanxi Province in 2014, after screening we take the remaining 817 enterprises as the sample data. First, through making some descriptive analysis for the Operation performance and the loss characteristics of the foreign enterprises in Shaanxi, we find the foreign enterprises' loss rate is obviously positive with Scale and YEAR. Then, we combine the conclusion of the descriptive analysis, plug the main factors into the logistic regression model, get the Logistic regression equation, and find the overall losses of foreign enterprises in Shaanxi are related to LnScale, YEAR, DAR and TAT. Finally, we draw some conclusions.
\end{abstract}

Keywords: Foreign direct investment, Operation performance, Influence factors, Logistic regression

\section{Introduction}

As the international capital is getting more dynamic and sizeable, FDI has become the main type of capital flows [1], the use of FDI has been expanded, and it's the channel to get the external resources in developing country. With the economy reform going in-depth, our government also tries our best to attract the FDI [2]. According to Commerce Ministry statistics, 26575 foreign-invested enterprises were approved in 2015 , with growth of $11.8 \%$ year-on-year. The actual use of foreign capital reached RMB 78.135 billion by 2015 , rose $6.4 \%$ over 2014 . It also proves that investors remained upbeat about China's market although we are facing the forbidding challenges of the slower economic growth, rising labor costs, increased competition of low-cost manufacturing [3], [4]. But in recent years many foreign-investment enterprises are largely in operational losses and nearly loss year after year [5], [6]. So we had to guess the true cause of the widespread losses of the foreign-invested enterprise.

\section{Present management situation of FDI}

According to the Statistics Bureau of Shaanxi in 2014, the foreign capital actually utilized of Shaanxi is increasing in recent years, and the concrete rising trend is shown in Figure 1 below.

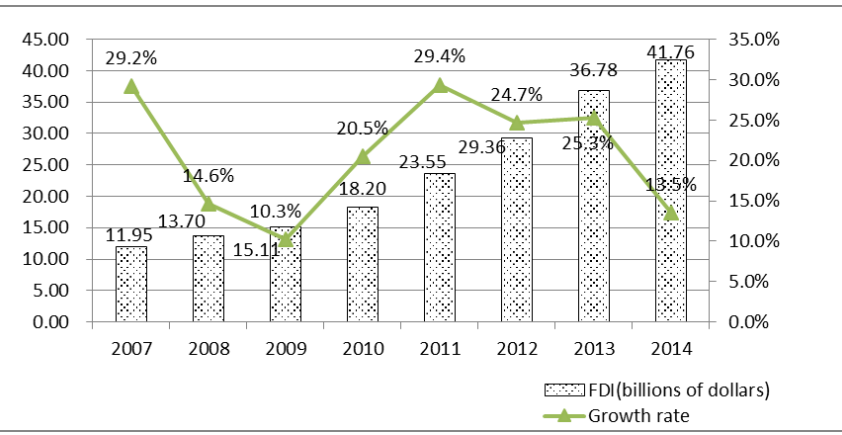

Figure 2: The loss of seven main industries
According to the Commerce Department of Shaanxi, the profession loss rate of 10 industries is over $50 \%$ in the foreign-invested industries of Shaanxi. From the figure 2, we can see in the seven main foreign-invested industries of Shaanxi, the Leasing \& Commercial service has the highest loss rate which reached $74.42 \%$, and the next is Hotels \& Catering service, these data could explain a lot about the third industry of Shaanxi is lack of social development, the relevant studies have shown that there are many similarities in other provinces [7].

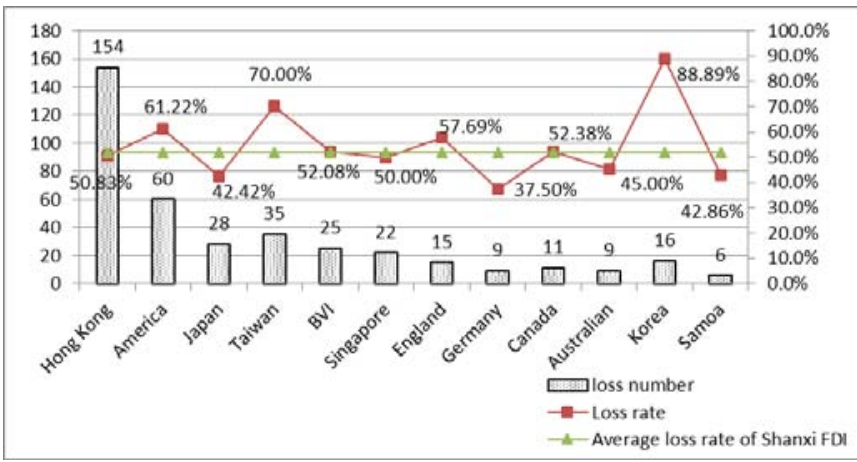

Figure 3: Main foreign investors' loss status of Shaanxi in 2013

In the early 1990 's, China had become the biggest FDI host country among developing countries and regions. And it exceeded the USA in 2003, became the first FDI importing country all over the world [8]. In the above chart, we can see the FDI from different countries has different loss rate, there are 8 district of the main foreign investors' loss rate is over $50 \%$. Among them, the loss rate of Korea is the highest, next is Taiwan, America. 


\section{International Journal of Science and Research (IJSR) \\ ISSN (Online): 2319-7064}

Index Copernicus Value (2013): 6.14 | Impact Factor (2014): 5.611

\section{Model and method}

\subsection{The Logistic regression model}

There are two ways of an enterprise's operating states: loss and not loss. According to the domestic and foreign related to achievement of study, we could create a Logistic regression model first because this is a two-valued variable.

$$
P(Y)=\frac{e^{\alpha+\sum_{i=1}^{m} \beta_{i}^{*} x_{i}}}{1+\mathrm{e}^{\alpha+\sum_{i=1}^{\mathrm{m}} \beta_{i}^{*} x_{i}}}=\frac{1}{1+\mathrm{e}^{-\left(\alpha+\sum_{i=1}^{m} \beta_{i}^{*} x_{i}\right)}}
$$

In the above model, we assume $\mathrm{P}$ to denote a probability when the enterprise is defective: $\mathrm{Y}=1$, and then Logit $\mathrm{P}=$ $\mathrm{Ln}[\mathrm{p} /(1-\mathrm{p})]$. We used constant $\alpha$ to describe the natural logarithm of the ratio of loss and not loss without any regard to any influence factor. We used the regression coefficient $\beta_{\mathrm{i}}$ to describe the ratio of the probability of an event occurs and not occurs when a single factor changes by one unit. So the deformed equation is:

$$
\operatorname{Ln}\left(\frac{p}{1-p}\right)=\alpha+\sum_{i=1}^{m} \beta_{i} *_{x_{i}}=\operatorname{Logit}(P)
$$

Value ranges: P: $0 \sim 1$, Logit P: $-\infty \sim+\infty$

Because of the dependent variable is binary variable, so we define any profits are negative as loss-generating enterprises irrespective of the extent of its losses, any profits are positive as profitable firm irrespective of the extent of its profit. With our present data, we need to transform the performance into categorical variable. If loss, we get number 1 , if not we get number 0 . The probability of loss is $\mathrm{P}$, then the probability of not loss is (1-p), let the $\operatorname{Ln}[\mathrm{P} /(1-\mathrm{P})]$ as the dependent variable. We want to research the possible reasons that cause the operating loss of the FDI for future study, so we assume that the loss of FDI is influenced by 5 main factors, including enterprise scale, operating time, foreign equity ratio, Debt-to-assets ratio, total assets turnover. So in order to determine different factors have different impacts, we adopting these variables when building logistic regression model.

Dependent Variable: $\mathrm{Y}=1$ (loss); $\mathrm{Y}=0$ (not loss)

Independent variable: FER-foreign equity ratio; LnScale-enterprise scale; YEAR-operating time; DAR - Debt-to-assets ratio; TAT — total assets turnover

\subsection{Analysis of regression}

By the Logistic regression model, we may import the Two-value variable $Y$ and the five independent variables into the model during a post-processing phase. In our program, we get the following output.

\begin{tabular}{|c|c|c|c|}
\hline \multicolumn{2}{|c|}{ Unweighted Cases ${ }^{\mathrm{a}}$} & $\mathrm{N}$ & Percent \\
\hline \multirow{3}{*}{ Selected Cases } & Included in Analysis & 817 & 100.0 \\
\hline & Missing Cases & 0 & .0 \\
\hline & Total & 817 & 100.0 \\
\hline \multicolumn{2}{|c|}{ Unselected Cases } & 0 & .0 \\
\hline \multicolumn{2}{|c|}{ Total } & 817 & 100.0 \\
\hline
\end{tabular}

Table 1: Case Processing Summary
Table 2 Dependent Variable Encoding

\begin{tabular}{|c|c|}
\hline Original Value & Internal Value \\
\hline loss & 0 \\
\hline Not loss & 1 \\
\hline
\end{tabular}

Table 3: Omnibus Tests of Model Coefficients

\begin{tabular}{|l|l|l|l|l|}
\hline \multicolumn{2}{|c|}{} & Chi-square & df & Sig. \\
\hline \multirow{3}{*}{ Step 1 } & Step & 198.734 & 5 & .000 \\
\cline { 2 - 5 } & Block & 198.734 & 5 & .000 \\
\cline { 2 - 5 } & Model & 198.734 & 5 & .000 \\
\hline
\end{tabular}

Table 4: Model Summary

\begin{tabular}{|c|c|c|c|}
\hline Step & $\begin{array}{c}-2 \text { Log } \\
\text { likelihood }\end{array}$ & $\begin{array}{c}\text { Cox \& Snell } \\
\text { R Square }\end{array}$ & $\begin{array}{c}\text { Nagelkerke } \\
\text { R Square }\end{array}$ \\
\hline 1 & $932.692^{\mathrm{a}}$ & .216 & .288 \\
\hline
\end{tabular}

a. Estimation terminated at iteration number 5 because parameter estimates changed by less than .001 .

From the table 1, we can see the selected cases are 817 enterprises, it means that every foreign enterprise was selected. The analysis results illustrates that the regression model is significant because the sig. of the model in table 3 is approved by significant testing. From the model summary in table 4 , we can see the log of maximum likelihood squared is very big, it is significant obviously.

\begin{tabular}{|c|c|c|c|c|c|}
\hline & \multirow{3}{*}{\multicolumn{2}{|c|}{ Observed }} & \multicolumn{3}{|c|}{ Predicted } \\
\hline & & & \multicolumn{2}{|c|}{$\mathrm{Y}$} & \multirow[t]{2}{*}{ Percentage Correct } \\
\hline & & & 0 & 1 & \\
\hline \multirow{3}{*}{ Step 1} & \multirow{2}{*}{ Y } & 0 & 277 & 116 & 70.5 \\
\hline & & 1 & 88 & 336 & 79.2 \\
\hline & Overall Percentage & & & & 75 \\
\hline \multicolumn{6}{|c|}{ a. The } \\
\hline
\end{tabular}

Table 5 Classification Table ${ }^{\mathrm{a}}$

The Classification Table shows us that the not loss foreign enterprises are 393 , the model predicted there are 277 cases, so the correct rate is $70.5 \%$. In the same way, the model predicted loss foreign enterprises' correct rate is $79.2 \%$.

Table 6: Variables in the Equation

\begin{tabular}{|c|c|c|c|c|c|c|c|}
\hline \multicolumn{2}{|c|}{} & B & S.E. & Wald & df & Sig. & Exp (B) \\
\hline \multirow{5}{*}{ Step 1 } & FER & 0.035 & 0.251 & 0.02 & 1 & 0.888 & 1.036 \\
\cline { 2 - 8 } & LnScale & -0.254 & 0.033 & 60.531 & 1 & 0 & 0.776 \\
\cline { 2 - 8 } & YEAR & -0.056 & 0.015 & 13.797 & 1 & 0 & 0.945 \\
\cline { 2 - 8 } & TAT & -0.941 & 0.118 & 63.736 & 1 & 0 & 0.39 \\
\cline { 2 - 8 } & DAR & 0.809 & 0.286 & 8.023 & 1 & 0.005 & 2.245 \\
\cline { 2 - 8 } & Constant & 2.859 & 0.37 & 59.59 & 1 & 0 & 17.437 \\
\hline
\end{tabular}

a. Variable(s) entered on step 1: FER, LnScale, YEAR, TAT, DAR.

From the final table 6, we can see the coefficients of the variables in the regression equation are significant except the foreign equity ratio. That illustrates this variable is statistically non-significant. And the remaining variables are significant, including enterprise scale, operating time, Debt-to-assets ratio and total assets turnover. When setting up the model we eliminate the foreign equity ratio, and then plug the other variables into the Logistic regression equation, we get the following equation.

$$
P=\frac{1}{1+e^{-(2.859-0.254 \text { LnScale-0.056YEAR+0.809DAR-0.941TAT })}}
$$




\section{International Journal of Science and Research (IJSR) \\ ISSN (Online): 2319-7064}

Index Copernicus Value (2013): 6.14 | Impact Factor (2014): 5.611

The $\mathrm{P}$ represents the probability of the foreign-invested enterprises' loss in Shaanxi, if it is close to 1 , the enterprise is more likely to be loss. From the type can also be seen, if the smaller the enterprises is, the shorter the operating time is, the hard the Debt-to-assets ratio is, the smaller the total assets turnover is, the $\mathrm{P}$ is higher, and the possibility of foreign investment losses will be higher.

Plugging the deformed Logit(P) into the equation, we get:

$\operatorname{Logit}(P)=\operatorname{Ln}\left(\frac{p}{1 p}\right)=2.859-0.254$ LnScale -0.056 YEAR +0.809 DAR -0.941 TAT

As shown in the above model, Logit( $\mathrm{P})$ has negative correlation with enterprise scale, but it is positively correlative to operating time, Debt-to-assets ratio and total assets turnover.

\section{Conclusion}

The phenomenon that the foreign-invested enterprises are largely in operational losses increased dramatically. About the cause of this phenomenon is attracted wide attention by Chinese academic circles. Nevertheless, there are controversies in the studies of this aspect and a consensus has still not been reached. This article focuses on the influence factors that the large operational losses of FDI by using the data of 817 foreign-invested enterprises to carry out empirical study. According to the above empirical study we can draw the following conclusions: The loss probability of FDI in Shaanxi is related to the enterprise scale, operating time, Debt-to-assets ratio and total assets turnover of the company. With the scale of company increasing, operating time is longer, total assets turnover is bigger, the possibility of turning foreign-invested enterprises into a profitable company become more likely, which confirms the lack of investment. Thus it can be seen that underinvestment is the one of the main causes of the difference between loss and profit. The analysis of the results also showed that Debt-to-assets ratio as a valuable indicator of capital structure which is another major factor of the foreign-invested enterprises' loss.

The following channels for improving the performance of foreign enterprises are put forward based on empirical study results.

\section{Set up more micro-credit companies}

The study result shows that the loss of foreign companies greatly depends on the enterprise-scale. Small and medium-sized foreign companies could not finance via listing as large foreign companies. A company in a new and strange situation that the culture is different will be more difficult for it to raise more capital. If that is so, then we are entering a vicious cycle, we didn't have enough money to scale up, then it will be more likely to become losses. So try to develop the transfer of economic assets and pledge of accounts receivable, and strengthen the introduction of foreign - invested banks is necessary.

\section{Accelerate transformation of growth modalities and paced up industrial restructuring}

It can be seen that the manufacturing industry is the largest business for foreign investment from the actual use of FDI over years in Shaanxi. Most of them are only responsible for the production of the product, only pursuing the speed of producing and developing the China market. From the YEAR variable, we can see the foreign companies are moving towards to improve the operating quality and risk-resisting ability. These foreign companies have realized the transition from 'exchange market for technology' to 'exchange market for talent' on the basis of ever-widening experience. Therefore, we should be focused on guiding foreign companies to integrate and optimize the traditional service, extending the chain to higher-end services. So the optimization and upgrading of FDI's industrial structure in Shaanxi totally relying on how to encourage the developing of advanced manufacturing, high-tech industry and modern service industry.

\section{Change preferential policy to quality service, improve the soft environment of investment}

From the long run, a stable and standard investment environment is more important than the general preferential policy [9]. There are four points we should keep in mind when promoting the services. First, creating a good working environment and living condition, reducing time and links of the approval and increasing the efficiency of it [10]. Second, help the FDI to deepen the emerging markets, analyzing the influence of the macro-environment to foreign companies, enhancing the initiative and predictability. Third, increase more connection with the domestic enterprises, and make the relationship more closely. Last, changing the -atacting capital" into - seetcing better capital", try to promote the combination of wits and investment. Improving the performance of foreign capital, promote the industrial and economic restructuring.

Finally, the large loss of FDI in Shaanxi is not only influenced by these individual causes, but also influenced by the current economic and social environment. So how to eliminate these influences of the macro-environment is worthy of serious and deep consideration.

\section{References}

[1] Moon H C, Roehl T W. Unconventional foreign direct investment and the imbalance theory [J]. International Business Review, 2001, 10(2): 197-215.

[2] Zhao C, Du J. Causality between FDI and economic growth in China [J]. Chinese Economy, 2007, 40(6): 68-82.

[3] Alfaro L, Kalemli-Ozcan S, Sayek S. FDI, productivity and financial development [J]. The World Economy, 2009, 32(1): 111-135.

[4] Whalley J, Xian X. China's FDI and non-FDI economies and the sustainability of future high Chinese growth $[\mathrm{J}]$. China Economic Review, 2010, 21(1): 123-135.Xu D, Pan Y, Wu C, et al.

[5] Performance of domestic and foreign-invested enterprises in China [J]. Journal of World Business, 2006, 41(3): 261-274.

[6] Verbeke A, Brugman P. Triple-testing the quality of multinationality performance research: An internalization theory perspective [J]. International Business Review, 2009, 18(3): 265-275. 


\section{International Journal of Science and Research (IJSR) \\ ISSN (Online): 2319-7064 \\ Index Copernicus Value (2013): 6.14 | Impact Factor (2014): 5.611}

[7] Zhao Z, Zhang K H. FDI and industrial productivity in China: Evidence from panel data in 2001-06[J]. Review of Development Economics, 2010, 14(3): 656-665.

[8] $\mathrm{Du} \mathrm{J,} \mathrm{Lu} \mathrm{Y,} \mathrm{Tao} \mathrm{Z.} \mathrm{Economic} \mathrm{institutions} \mathrm{and} \mathrm{FDI}$ location choice: Evidence from US multinationals in China [J]. Journal of comparative Economics, 2008, 36(3): 412-429.

[9] Büthe T, Milner H V. The politics of foreign direct investment into developing countries: increasing FDI through international trade agreements? [J]. American Journal of Political Science, 2008, 52(4): 741-762.

[10] Davies K. Inward FDI in China and its policy context in 2012[J]. Transnational Corporations Review, 2012, 4(4): 4-18.

\section{Author Profile}

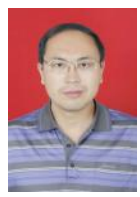

Tao Wang working as an Associate Professor in School of XIDIAN UNIVERSITY since 2006. His specialization lies in Financial Management and Transnational Investment.

Duo Wang received bachelor degree in Management from the School of XIDIAN UNIVERSITY, China during 2010 and 2014. She is now pursuing Master degree since 2014 under the guidance of Prof. Tao Wang. Her specialization area is Finance. 